\section{In vivo two-photon fluorescent imaging of fluoride with a desilylation-based reactive probe $\dagger$}

\author{
Dokyoung Kim, ${ }^{a}$ Subhankar Singha, ${ }^{a}$ Taejun Wang, ${ }^{b}$ Eunseok Seo, ${ }^{b}$ Jun Ho Lee, ${ }^{b}$ \\ Sang-Joon Lee, ${ }^{* b}$ Ki Hean Kim ${ }^{* b}$ and Kyo Han Ahn*a
}

Received 4th August 2012, Accepted 31st August 2012

DOI: $10.1039 / \mathrm{c} 2 \mathrm{cc} 35668 \mathrm{f}$

\begin{abstract}
A two-photon excitable molecular probe for fluoride, developed based on a fluoride-specific desilylation reaction, is demonstrated to be useful for fluorescent imaging of fluoride ions in live zebrafish by one-photon as well as two-photon microscopy for the first time.
\end{abstract}

Fluoride is added to drinking water to promote dental health in some countries (water fluoridation). There is consistent evidence that water fluoridation, however, results in the development of dental fluorosis. ${ }^{1}$ To prevent dental fluorosis more appropriate use of other fluoride sources are recommended for children. Fluoride is also found in many common household products, including toothpaste and dietary supplements. Other uses of fluoride are as glass-etching and chrome-cleaning agents, and insecticides and rodenticides. An acute intake of fluoride can cause gastric and kidney disorders, skeletal fluorosis, and urolithiasis in humans. ${ }^{2}$ Therefore, tools that allow us to detect fluoride in our environment as well as to monitor fluoride in living species are indispensable.

The fluorescent analysis method has received continuing attention owing to its highly sensitive and handy features as well as its versatility for bioimaging purpose. Accordingly, various fluorescent probes for fluoride have been developed in recent years based on novel sensing strategies. ${ }^{3}$ Most of the known fluorescent probes for fluoride are based on three molecular interactions: hydrogen bonding between fluoride and $\mathrm{NH}$ hydrogen (amide, pyrrole, indole, urea and thiourea), ${ }^{4}$ boron-fluoride complexation, ${ }^{5}$ and fluoride mediated desilylation. ${ }^{6}$ The hydrogen bonding approach is essentially not effective in aqueous media because of the strong hydration propensity of fluoride ions. Also, the boron-fluoride complexation approach is not suitable for biological applications, owing to the cytotoxicity and instability issues, in addition to the low selectivity in cellular environments. The fluoride mediated desilylation approach,

${ }^{a}$ Department of Chemistry, Center for Electro-Photo Behaviors in Advanced Molecular Systems, POSTECH, San 31, Hyoja-dong, Pohang, 790-784, Republic of Korea.E-mail: ahn@postech.ac.kr

${ }^{b}$ Department of Mechanical Engineering and Division of Integrative Biosciences and Biotechnology of Mechanical Engineering,

POSTECH, San 31, Hyoja-dong, Pohang, 790-784,

Republic of Korea

$\dagger$ Electronic supplementary information (ESI) available: Synthesis and characterization of the compounds, absorption and emission, NMR titration, $\mathrm{pH}$ profile, cell viability, and other TPM imaging data including video clips. See DOI: 10.1039/c2cc35668f originally devised by Kim and Swager, ${ }^{6 a}$ can alleviate these problems and thus has received growing interest recently. However, for bioimaging applications existing probes have drawbacks to some extent, and so far only two probes have been evaluated for the fluorescent imaging of fluoride in cells. ${ }^{6 d, e}$ Considering the widespread use of fluoride in daily life, and, furthermore, its implications in biological effects, a fluorescent probe that enables the detection and imaging of fluoride ions in living species is highly demanded. Herein, we report such a probe that shows high sensitivity and selectivity toward fluoride ions, and, furthermore, that allows two-photon fluorescent imaging in living species for the first time.

Two-photon absorbing materials have drawn considerable attention during the last decade for their potential applications in optical imaging by two-photon microscopy (TPM), which has several advantageous features over one-photon microscopy (OPM) such as increased penetration depth, lower tissue autofluorescence and self-absorption, and very high resolution, in addition to the reduced photodamage and photobleaching. ${ }^{7}$ Recently, we developed $\pi$-extended coumarins as novel twophoton absorbing materials. ${ }^{8}$ One of the compounds, iminocoumarin 1, emits at a longer wavelength with higher quantum yield (585 nm, $\left.\Phi_{\mathrm{F}}=0.63\right)$ compared to acedan $\left(501 \mathrm{~nm}, \Phi_{\mathrm{F}}=\right.$ $0.52)$ and coumarin $153\left(548 \mathrm{~nm}, \Phi_{\mathrm{F}}=0.50\right)$, and has a good two-photon absorption cross-section value $(\mathrm{GM}=180)$. Based on the unique two-photon absorbing property of $\mathbf{1}$, we are exploring its precursors that would yield 1 through analytespecific chemical transformations. A variety of chemical transformations have been creatively combined with fluorogenic materials to develop such "reactive" probes in recent years. Herein, we demonstrate that tert-butyldimethylsilyl (TBDMS) ether $\mathbf{P} \mathbf{1}$ is a valuable probe that enables fluorescent imaging of fluoride ions in a live vertebrate, zebrafish (Scheme 1).

P1 can be readily synthesized starting from commercially available naphthalene-2,7-diol. ${ }^{10}$ Experimental procedures and characterization data are given in the ESI. $\dagger$

P1 displayed one major absorption band centred at $460 \mathrm{~nm}$ (Fig. S1, ESI $\dagger$ ). When excited at $460 \mathrm{~nm}$, the probe solution barely emitted; however, upon treatment with fluoride it emitted strongly as iminocoumarin 1 was produced (Scheme 1). Cleavage of the TBDMS group and formation of $\mathbf{1}$ were monitored by NMR titrations (Fig. S2, ESI $\dagger$ ). Fluorescence titration of the probe with $\mathrm{F}^{-}$was carried out in a HEPES buffer solution 
<smiles>CCCCO[Si](C)(C)Oc1cc2cc(N(C)[O-])ccc2cc1/C=C(\C#N)C(C)(C)C</smiles><smiles>CN(C)c1ccc2cc3cc(C#N)c(=N)oc3cc2c1</smiles>

Scheme 1 Sensing scheme of fluoride with P1.
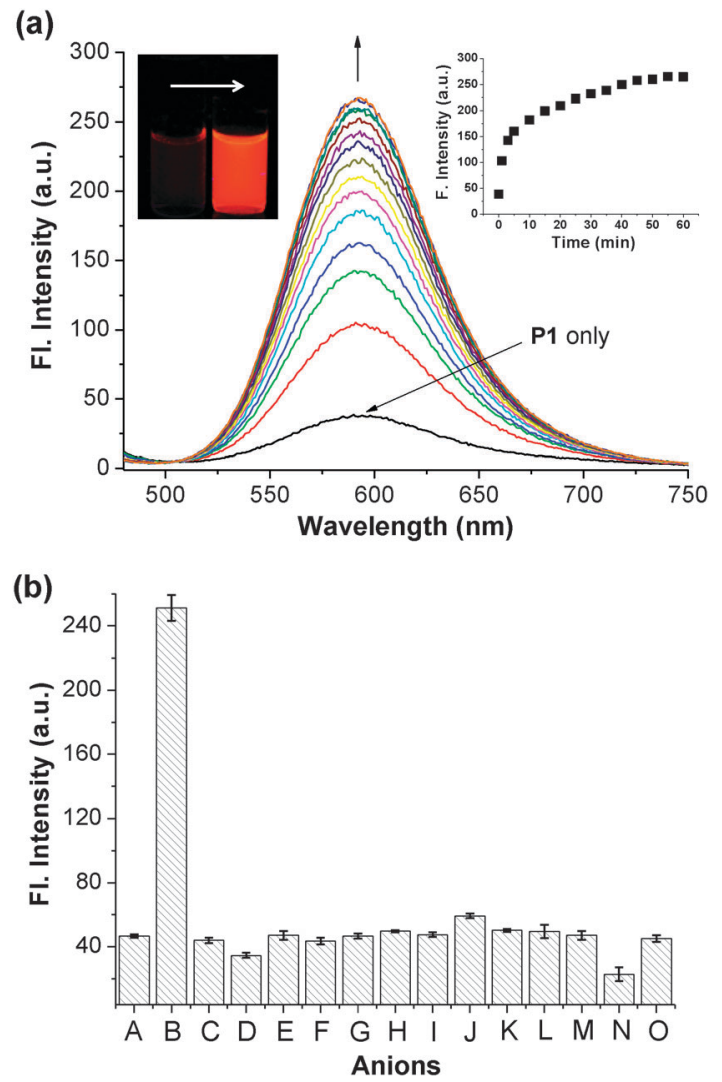

Fig. 1 (a) Fluorescence response of $\mathbf{P 1}(20 \mu \mathrm{M})$ toward $\mathrm{F}^{-}(\mathrm{NaF}$, $20 \mathrm{mM}$ ) in $\mathrm{pH} 7.4$ buffer ( $10 \mathrm{mM}$ HEPES containing $20 \% \mathrm{CH}_{3} \mathrm{CN}$ ) obtained under excitation at $460 \mathrm{~nm}$. Each spectrum was recorded at $3,5,7$, and 10-60 $\mathrm{min}$ (5 min interval after $10 \mathrm{~min}$ ) after mixing together. Left inset: photos of $\mathbf{P 1}$ in the solution before and after treatment with $\mathrm{F}^{-}$. Right inset: a plot of fluorescence intensity, estimated as the peak height at $595 \mathrm{~nm}$, depending on time. (b) Relative fluorescence intensity data obtained for a mixture of P1 $(20 \mu \mathrm{M})$ and each of the anions ( $20 \mathrm{mM}$ as $\mathrm{Bu}_{4} \mathrm{~N}^{+}$salts, $20 \mathrm{mM}$ Cys, and $1 \mathrm{mg} \mathrm{mL}^{-1} \mathrm{BSA}$ ) in $\mathrm{pH} 7.4$ buffer (10 mM HEPES containing $20 \% \mathrm{CH}_{3} \mathrm{CN}$ ), measured after $1 \mathrm{~h}$ under excitation at $460 \mathrm{~nm}$ (The fluorescence intensity was estimated as the peak height at $595 \mathrm{~nm}$; error bars were obtained from 3 times experiments): (A) P1, (B) $\mathrm{F}^{-}$, (C) $\mathrm{Cl}^{-}$(D) $\mathrm{CN}^{-}$, (E) $\mathrm{Br}^{-}$, (F) $\mathrm{I}^{-}$, (G) $\mathrm{NO}_{3}^{-}$, (H) $\mathrm{HSO}_{4}^{-}$, (I) $\mathrm{ClO}_{4}^{-}$, (J) $\mathrm{PF}_{6}^{-}$, (K) $\mathrm{CH}_{3} \mathrm{COO}^{-}$, (L) $\mathrm{SCN}^{-}$, (M) $\mathrm{N}_{3}^{-}$, (N) Cys, and (O) BSA.

(10 mM, pH 7.4) containing acetonitrile ( $20 \%$ by volume). Upon addition of $\mathrm{F}^{-}$, a significant fluorescence enhancement was observed within $10 \mathrm{~min}$ and became saturated after $1 \mathrm{~h}$ (Fig. 1a). The emission was identified to result from 1, by comparing it with the emission from an authentic sample of 1; both samples showed the same emission bands centred at $595 \mathrm{~nm}$ (Fig. S2, ESI $\dagger$ ).

The fluorescence response of the probe toward various other anions was evaluated under the optimized conditions. Only $\mathrm{F}^{-}$ induced emission change as already demonstrated by other silyl ether type probes, and other anions $\left(\mathrm{Cl}^{-}, \mathrm{CN}^{-}, \mathrm{Br}^{-}, \mathrm{I}^{-}\right.$, $\mathrm{NO}_{3}{ }^{-}, \mathrm{HSO}_{4}{ }^{-}, \mathrm{ClO}_{4}{ }^{-}, \mathrm{PF}_{6}{ }^{-}, \mathrm{CH}_{3} \mathrm{COO}^{-}, \mathrm{SCN}^{-}$, and $\mathrm{N}_{3}{ }^{-}$) did not interfere with the fluoride-mediated desilylation process even at 10 times higher concentration with respect to that of $\mathrm{F}^{-}$(Fig. $1 \mathrm{~b}$ and Fig. S3, ESI $\dagger$ ). Cysteine (Cys) seems to cause small interference to the sensing process, but did not hamper the fluorescence imaging of fluoride in cells and living species. Such a high selectivity of the probe toward $\mathrm{F}^{-}$ demonstrates again the effectiveness of the reaction based approach that uses the strong affinity of fluoride ions toward a silicone atom.

A good linear relationship between the fluorescence intensity and concentration of $\mathrm{F}^{-}$was observed for a wide concentration range $(0-1600$ ppm, Fig. S4, ESI $\dagger)$. On the basis of the criterion of the signal-to-noise ratio of more than three $(\mathrm{S} / \mathrm{N} \geq 3)$, the limit of detection of $\mathrm{F}^{-}$with the probe was estimated to be below $4 \mathrm{ppm}$, the allowed concentration level in drinking water set by USEPA. This is a comparable value to the lowest detection limit obtainable by known fluorescence probes. $^{6 d, e}$ Also, $\mathbf{P 1}$ showed good stability for a wide range of $\mathrm{pH}$ values, from 4 to 10 (Fig. S5, ESI $\dagger$ ).

To further demonstrate the potential of P1 for fluorescent imaging of $\mathrm{F}^{-}$in living species, we carried out imaging studies with live B16F10 cells by both one- and two-photon microscopy. P1 showed low toxicity to the cultured cells in the wide concentration range of $10-200 \mu \mathrm{M}$, as determined for B16F10 cells using the CCK-8 method (Fig. S6, ESI $\dagger$ ). Also, P1 is cell permeable as shown below. Sample plates containing the cell line, one treated with the probe only and the other treated with both the probe and $\mathrm{F}^{-}$(treated with $20 \mathrm{mM} \mathrm{NaF}$ for $60 \mathrm{~min}$ ), were fluorescently imaged by OPM and TPM. The red fluorescence images of cells obtained by OPM clearly indicated the presence of fluoride (Fig. S7, ESI $\dagger$ ). TPM images were recorded under excitation at $880 \mathrm{~nm}$ with $40 \mathrm{~mW}$ laser power. Under the excitation conditions, autofluorescence is not detected (Fig. 2a). From the cell line treated only with P1, very weak fluorescence is observable (Fig. 2b). In contrast, in the case of the cell line treated with both $\mathbf{P 1}$ and $\mathrm{F}^{-}$, bright red two-photon images are evident from the cytosolic area (Fig. 2c).

On the basis of successful cell imaging experiments with P1, next we investigated fluorescence imaging of fluoride ions in a living vertebrate, 4-day-old albino zebrafish. We monitored distribution of fluoride ions in the zebrafish for three different
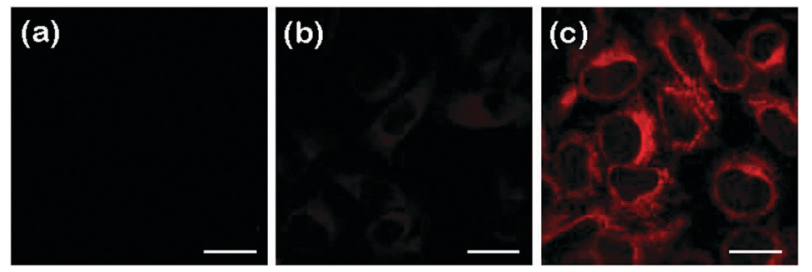

Fig. 2 Two-photon fluorescent images of B16F10 cells (mouse skin cancer cell line). All images were recorded under excitation at $880 \mathrm{~nm}$. (a) Images of B16F10 cells only; (b) image of B16F10 cells incubated with P1 $(20 \mu \mathrm{M})$ in PBS buffer for $30 \mathrm{~min}$ at $37^{\circ} \mathrm{C}$; (c) image of B16F10 cells incubated with P1 $(20 \mu \mathrm{M})$ for $30 \mathrm{~min}$ at $37^{\circ} \mathrm{C}$ followed by treatment with $20 \mathrm{mM} \mathrm{NaF}$ in PBS buffer for $60 \mathrm{~min}$ at $37^{\circ} \mathrm{C}$. Scale bar: $20 \mu \mathrm{m}$. View area: $110 \mu \mathrm{m} \times 110 \mu \mathrm{m}$. 


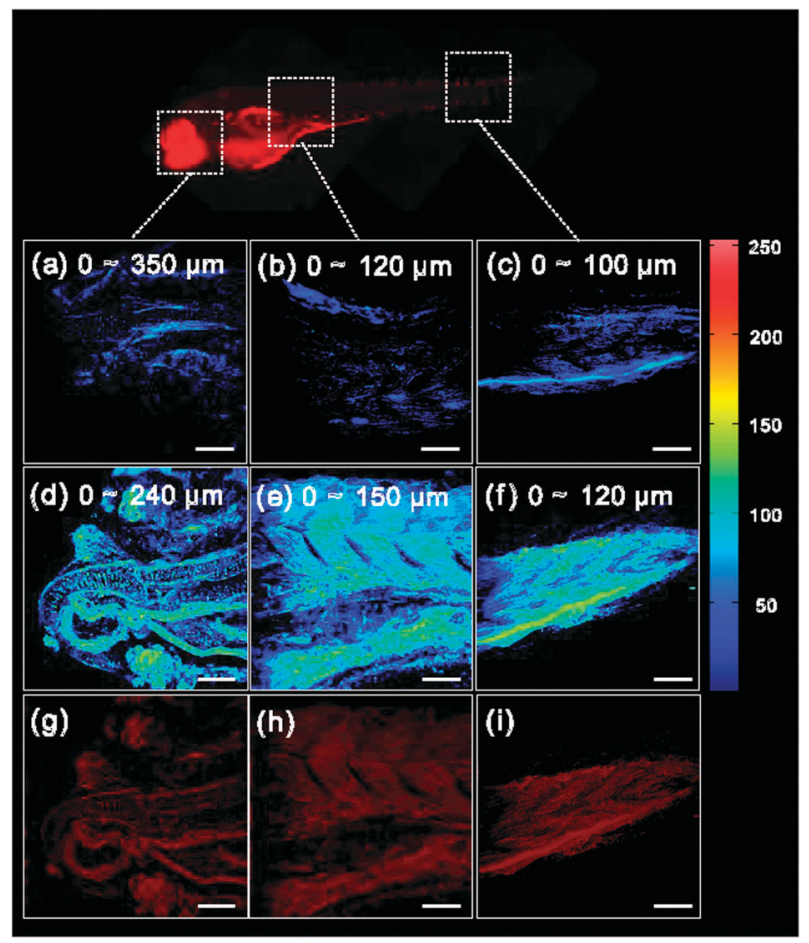

Fig. 3 Accumulated TPM fluorescent images for the three parts of zebrafish: $(\mathrm{a}-\mathrm{c})$ incubated only with probe $\mathbf{P 1}(20 \mu \mathrm{M})$ for $30 \mathrm{~min}$ at $29{ }^{\circ} \mathrm{C}$; (d-i) incubated with probe $\mathbf{P 1}(20 \mu \mathrm{M})$ for $30 \mathrm{~min}$ followed by with $\mathrm{F}^{-}(5 \mathrm{mM})$ for $120 \mathrm{~min}$ at $29{ }^{\circ} \mathrm{C}$ : $(\mathrm{a}-\mathrm{f})$ intensity data; $(\mathrm{g}-\mathrm{i})$ fluorescence images of $\mathrm{d}-\mathrm{f}$. Each image was constructed by image stacking for $0-350 \mu \mathrm{m}$ depth, with a $2 \mu \mathrm{m}$ imaging depth step. Scale bar: $50 \mu \mathrm{m}$. View area: $300 \mu \mathrm{m} \times 300 \mu \mathrm{m}$.

parts depending on the incubation time of the probe and fluoride (Fig. S8, ESI $\dagger$ ). First, we examined zebrafish treated only with P1 $(20 \mu \mathrm{M})$ depending on the incubation time, by looking at the specific depth where we could detect a maximum fluorescence for each part of the fish (head, abdomen, and tail parts). As P1 itself shows slight fluorescence, we can observe only weak or negligible fluorescence depending on the parts (Fig. S8d, ESI $\dagger$ ). When these probe-treated samples were incubated further with fluoride $(5 \mathrm{mM})$, bright fluorescence was observed for all the parts (Fig. S8e, ESI $\dagger$ ). These results indicate that fluoride ions are distributed throughout the whole body of the zebrafish. A stronger intensity was observed in the abdomen and tail parts for $2 \mathrm{~h}$ incubated samples compared with the $30 \mathrm{~min}$ incubation one, while fluorescence increase in the head part is apparent after $4 \mathrm{~h}$ incubation (Fig. S9, ESI $\dagger$ ). As we used different zebrafish for each data set (total 18 zebrafish), such a comparison of fluorescence intensity gives a qualitative picture for the distribution of fluoride ions. Fig. 3 shows a side view of zebrafish by OPM and accumulated fluorescence images for three selected parts by TPM. The collected TPM fluorescent images (Fig. 3a-f) show fine patterns between the bones (dark) and flesh area (bright), which indicates that penetration of fluoride into bones is slow within the given incubation period. Video clips show more clear images, which are given in the $\mathrm{ESI} \dagger$ (Fig. S10-S12).
In summary, a novel two-photon excitable molecular probe for fluoride has been developed and demonstrated to be useful for fluorescent imaging of fluoride in a live vertebrate for the first time. A precursor of a $\pi$-extended iminocoumarin thus prepared undergoes a fluoride-mediated desilylation to produce a two-photon absorbing iminocoumarin with excellent analyte selectivity and sensitivity. The probe enabled us to fluorescently image the presence of fluoride ions in cells as well as in the whole body of zebrafish in a spatial and timedependent manner by two-photon microscopy.

This work was supported by grants from the EPB center (R11-2008-052-01001) through National Research Foundation, Korea. K. H. Kim thanks financial support by the Bio \& Medical Technology Development Program (2011-0019619, 2011-0019632).

\section{Notes and references}

1 S. Ayoob and A. K. Gupta, Crit. Rev. Environ. Sci. Technol., 2006, 36, 433-487.

2 (a) E. B. Bassin, D. Wypij and R. B. Davis, Cancer, Causes Control, Pap. Symp., 2006, 17, 421-428; (b) S. X. Wang, Z. H. Wang, X. T. Cheng, J. Li, Z. P. Sang and X. D. Wang, Environ. Health Perspect., 2006, 115, 643-647; (c) Y. Yu, W. Wang, Z. Dong, C. Wan, J. Zhang, J. Liu, K. Xiao, Y. Huang and B. Lu, Fluoride, 2008, 41, 134-138.

3 (a) R. M. Duke, E. B. Veale, F. M. Pfeffer, P. E. Krugerc and T. Gunnlaugsson, Chem. Soc. Rev., 2010, 39, 3936-3953; (b) A. F. Li, J. H. Wang, F. Wang and Y. B. Jiang, Chem. Soc. Rev., 2010, 38, 3729-3745.

4 (a) Y. Qu, J. Hua and H. Tian, Org. Lett., 2010, 12, 3320-3323; (b) E. J. Cho, J. W. Moon, S. W. Ko, J. Y. Lee, S. K. Kim, J. Yoon and K. C. Nam, J. Am. Chem. Soc., 2003, 125, 12376-12377; (c) M. Boiocchi, L. D. Boca, D. Esteban-Gomez, L. Fabbrizzi, M. Licchelli and E. Monzani, J. Am. Chem. Soc., 2004, 126, 16507-16515; (d) M. Vazquez, L. Fabbrizzi, A. Taglietti, R. M. Pedrido, A. M. Gonzalez-Noya and M. R. Bermejo, Angew. Chem., Int. Ed., 2004, 43, 1962-1965; (e) T. Mizuno, W. H. Wei, L. R. Eller and J. L. Sessler, J. Am. Chem. Soc., 2002, 124, 1134-1135; (f) K. J. Chang, D. Moon, M. S. Lah and K. S. Jeong, Angew. Chem., Int. Ed., 2005, 44, 7926-7929.

5 (a) Z. Liu, M. Shi, F. Li, Q. Fang, Z. Chen, T. Yi and C. Huang, Org. Lett., 2005, 7, 5481-5484; (b) C. Chiu and F. P. Gabbai, J. Am. Chem. Soc., 2006, 128, 14248-14249; (c) T. W. Hudnall and F. P. Gabbai, Chem. Commun., 2008, 4596-4597; (d) X. Y. Liu, D. R. Bai and S. Wang, Angew. Chem., Int. Ed., 2006, 45, $5475-5478$.

6 (a) T. Kim and T. M. Swager, Angew. Chem., Int. Ed., 2003, 42, 4803-4806; (b) S. Y. Kim and J. Hong, J. Org. Chem., 2007, 9 , 3109-3112; (c) R. Hum, J. Feng, D. Hu, S. Wang, S. Li and G. Yang, Angew. Chem., Int. Ed., 2010, 49, 4915-4918; (d) S. Y. Kim, J. Park, M. Koh, S. B. Park and J. Hong, Chem. Commun., 2009, 4735-4737; (e) B. Zhu, F. Yuan, R. Li, Y. Li, Q. Wei, Z. Ma, B. Du and X. Zhang, Chem. Commun., 2011, 47, 7098-7100; (f) J. F. Zhang, C. S. Lim, S. Bhuniya, B. R. Cho and J. S. Kim, Org. Lett., 2011, 13, 1190-1193; $(g)$ P. Sokkalingam and C. Lee, J. Org. Chem., 2011, 76, 3820-3828.

7 (a) W. R. Zipfel, R. M. Willians and W. W. Webb, Nat. Biotechnol., 2003, 21, 1369-1377; (b) H. M. Kim and B. R. Cho, Chem.-Asian J., $2011,6,58-79$.

8 D. Kim, S. Sambasivan, H. Nam, K. H. Kim, J. Y. Kim, T. Joo, K. Lee, K. Kim and K. H. Ahn, Chem. Commun., 2012, 48, 6833-6835.

9 For a comprehensive review: M. E. Jun, B. Roy and K. H. Ahn, Chem. Commun., 2011, 47, 7583-7601.

10 I. Kim, D. Kim, S. Sambasivan and K. H. Ahn, Asian J. Org. Chem., 2012, 1, 60-64. 